\title{
Insights into colonial Australian life: early Australian pamphlets as social history
}

\author{
Ray Archee ${ }^{1,2, *}$ \\ ${ }^{1}$ School of Humanities and Communication Arts \\ ${ }^{2}$ University of Western Sydney, AUSTRALIA
}

\section{Email address:}

r.archee@uws.edu.au (R. Archee)

\section{To cite this article:}

Ray Archee. Insights into Colonial Australian Life: Early Australian Pamphlets as Social History, Social Sciences. Vol. 1, No. 1, 2012, pp. 7-14. doi: 10.11648/j.ss.20120101.12

\begin{abstract}
Pamphlets were an important medium of public debate in the 19th century, embracing key religious, political, social, and technological issues of the day, and providing instruction on a range of skills and tasks. They remain a valuable primary resource of relevance to a broad range of disciplines. However, pamphlets are under-utilized within research and teaching because they are typically difficult to locate and access. They are hard to find in the few research libraries in which they are housed, and such libraries often bundle these small publications together in large single volumes making referencing a daunting task. This paper analyses a selection of digital photographs from the 14,000 Australian colonial pamphlets held at the State Library of NSW, Sydney, Australia. The selected photographs not only form an online archive of the earliest examples of Australian technical and instructional writing, but also provide insight into the everyday life, interests, and activities of people around the nation. Through illustration and analysis this paper will provide fresh insight into Australian colonial life and early instructional writing.
\end{abstract}

Keywords: Pamphlets, Colonial Australian Life, Social History

\section{Introduction}

There is some debate as to the derivation of the word, "pamphlet". One possible origin is that it derives from the words for 12th century love Latin poems - Pamphilus seu de Amore [1]. The diminutive suffix, -et was perhaps added to denote the appearance of a small book with references to the pamphlet beginning in Anglo-Latin texts in the 14th century and in English writing in the 15th century. But it was not until the 18th century that the term came to denote its current meaning of a short controversial booklet [2]. What can be definitely stated it that the term has changed many times over the centuries with the rapid spread of printing, the rise of books and newspapers, and concomitant increases in literacy, travel and commerce.

Originally, a pamphlet referred to a small, separate book, usually unbound, and not large enough to constitute a volume on its own. Some bibliographers apply the term to everything less than 50 pages, others limit the term to two or three pages. Brevity and spontaneity were the pamphlet's main features, while its unique aim was to reflect some matter of current interest - religious, political, social or technical. Early English pamphlets contained poetry and/or prose but were not designed to last forever like books. Poor quality paper and ink, modest print runs and somewhat illegible text was very much the norm. Apart from a hypothetical general audience, many pamphlets were produced for a market of gentlemen who sought entertainment and titillation [1].

By the late 1500's in England, the pamphlet became a short vernacular work usually in quarto format, costing a few pennies and dealing with subjects of current interest, and social, political or religious issues. At this time pamphlets were often closely associated with slander or scurrilous behaviours. There are numerous references to pamphlets that promote the practice of witchcraft, and denigrate the Christian church of the time. On the Continent, pamphlets were also used to announce the birth of monstrous births that supposedly reflected social disturbance and religious trauma.

A slang, now-obsolete meaning of the word, "pamphlet" was that of a prostitute. Probably the reputation of a pamphlet as being a trashy booklet available for a few pennies was the main reason for this metaphorical usage. Late 16th century practice was thus deprecatory with pamphlets seen as small, insignificant, disposable, untrustworthy and 
altogether a waste of time. This is exactly why pamphlets were rarely collected, and probably why they were so poorly organised in the few libraries that possess them.

However pamphlets are an invaluable source of information because of the alternative, novel insight they provide into the interests of organisations and community groups, and the everyday lives of ordinary people. While the usual way our ancestors stayed in touch with the community was through word of mouth, in lieu of other media, early newspapers and books are typically used as the main resources for historical study. But ordinary citizens could not afford books, and newspaper circulations were quite small [3] and something of a rarity in country towns and rural areas. Given the large number of small publishers, and their independent status, pamphlets represent a comprehensive view of the main issues that concerned most levels of society. Thus the history of pamphlets represents changing public opinions more thoroughly than those expressed in books, which were always published after that opinion has changed [4].Without the existence of public libraries or any form of systematic adult education, pamphlets may also be seen as an early form of distance education $[5,6]$.

Rhetorical analysis of pamphlets is a typical method for analysing pamphlets occurring in a range of diverse disciplines and areas. For example pamphlets have been utilised to analyse: witchcraft [7], menopause[8], community welfare [9], fear appeals in health campaigns [10], smoking[11], and Victorian sexual mores [12].A popular methodology for analysing modern pamphlets, especially in relation to public health is content analysis of publications, for example, on issues such as AIDS [13], breast screening [14], cervical cancer[15], cystic fibrosis [16], and other diseases.

A classic book in the field of Technical Writing is Elizabeth Tebeaux's, The Emergence of a Tradition: Technical Writing in the English Renaissance, 1475-1640 [6]. Tebeaux traces the rise of the technical book and monograph in terms of formatting, style, and rhetorical impact upon readers of the time. Tebeaux analyses the style, format and language of early publications to reveal the important contribution that they have had to the modern ideas of technical instruction and to the growth of knowledge. In particular, the use of structure, graphics and tables allowed Renaissance authors' perception of the audience to change from one of prescription and didacticism to one of communication and learning.

Tebeaux's unique analysis describes a variety of technical genres which create a Renaissance technical writing typology thus providing a starting point for categorising early technical writing in general. Her eight categories are: Medical, Farming, Gardening, Household Management (especially cooking), Recreation, Military Science and Navigation, Self-Help, and Technologies.

\section{Method}

In 2004, the author discovered the collection of 14,000 pamphlets and ephemera housed at the State Library of NSW in Sydney, Australia making it certainly the largest collection of colonial Australian pamphlets in the world. Much of the State Library's collection was donated from the private collection of Australiana owned by David Scott Mitchell, a wealthy Sydney-born recluse. Apart from the huge cultural bequest of the thousands of early colonial books and monographs, D.S. Mitchell also collected pamphlets, almanacs, sermons, catalogues, lectures, and manuals spanning the Pacific - Australia and New Zealand for nearly the entire 19th century. Over the years, all the small and frail documents were organised into 700 hardbound volumes. It is from this collection that an archive of Australian colonial technical documents was created.

The technical/instructional significance of the Mitchell Library pamphlet collection is just one aspect of this archive. From inspection of the entire collection it is clear that early Australian pamphlets can be roughly divided into two main types: 1. religious, dealing with Christian issues, and 2. secular, dealing with pragmatic day-to-day activities. It is from the latter category that the author selected documents which depicted early instructional and policy writing. Over a period four months the technical pamphlets were bookmarked and digitally photographed without the use of flash. The resultant 649 photographs were then downsized using computer software for perusal on the Internet. The archive may be viewed at http://stc.uws.edu.au/gallery2. The archive retains the original numbering of the extant volumes from the State Library of NSW, but this does not reflect a chronology since the original ordering of the pamphlets and volumes was randomly organised. Thus, a handful of pamphlets have been duplicated since they appear in more than one volume.

All the available secular technical pamphlets were selected with the idea of depicting the kinds of ordinary activities which colonial Australians would have performed on a regular basis. Thus many catalogues, short magazines and record keeping documents were omitted from the archive since their function was distinct from the pedagogical intent of the technical pamphlets. Two hundred and twenty eight individual pamphlets were selected that met the following criteria: 1. it was a manual for performing a task or process; 2. it comprised rules and regulations for an organisation or institution.

\section{Results and Discussion}

\subsection{Genres of Colonial Pamphlets}

Many of the selected documents can be placed into one of Tebeaux's eight categories. However the archive contains documents, which necessitate the addition of seven extra categories seen below in Table 1. Arguably some of the new genres can be said to overlap with Tebeaux's original system, e.g. Tourism and Sporting Guides may be regarded as Recreation. But some of the colonial categories are completely novel to the epoch. Mining is obviously the most popular topic followed by Farming, and Tourism/Migration. The relatively large numbers of pamplets dealing with occult 
or the supernatural was surprising given the highly religious nature of the rest of the Mitchell collection. Also unexpected were documents dealing with the teaching of music to children, how to raise one's canary, and warnings about the perils of smoking, the latter showing a sophisticated concern for society and its problems.

Table 1. Tebeaux's originals and additional categories with frequency counts in brackets.

\begin{tabular}{ll}
\hline Tebeaux's Typology & Additional categories \\
\hline Medical (13) & Mining (30) \\
Farming (27) & Tourism \& Migration (21) \\
Gardening (18) & Sporting Guides (15) \\
Household Management (18) & Policies \& Rules (20) \\
Recreation (7) & Occult and supernatural (16) \\
Miltary Science \& Navigation (7) & Statistical Analyses (14) \\
Self-Help (7) & Education (10) \\
Technologies (5) & \\
\hline
\end{tabular}

In the two hundred years, from the Elizabethan era to Australian colonial times, ordinary people's lives had inevitably become more complex with many more activities taking up an individual's daily life. It is clear that normal people were neither completely exhausted by work commitments, nor excessively bored or idle. In both the large cities and small country towns, the publication and consumption of a large range of pamphlets indicates the country's predilection for numerous pragmatic and leisure pursuits that go far beyond the imagined lives of convicts, or their gaolers, and the depictions of colonial life found in recounts of the explorers, Aborigines, gold miners and bushrangers.

The exact audience for these early pamphlets is unknown. No records remain to inform us of their distribution area, or circulation numbers. Apart from titles and authors, the most that is recorded on the front of most pamphlets is the publisher, the year of publication, and place of publication.

It is often thought that colonial Australia was not a literate society, or only partly literate, but the existence of such a huge variety of content found in the pamphlets suggests that there was a reading class, which had the need to learn about a range of information and skills in the growing colony. There also seemed to exist a large number of local publishers, mainly in the large cities and but also in the country, necessary to cater for increasing demands for cheap, contemporary instructional and information guides.

In their article, Images of Women in Technical Books from the English Renaissance [18], Tebeaux and Lay concluded that women played an active role in certain key areas of social life. In particular, middle-class Renaissance women ran both the farm and the business when their husbands were away. By analysing books and their style, Tebeaux and Lay suggest that the areas of cooking, household management, gardening, medical treatment, midwifery, silkworm cultivation, animal husbandry, and estate management were designated roles for women in Renaissance times.It would follow that short pamphlets on similar topics would probably also be written for a predominantly female audience in colonial Australia. To this list one could add the following extra categories from Table 1 - the occult, teaching, perhaps even tourism guides. While these early pamphlets may be viewed as forerunners of today's 'womens' magazines, which tend to focus on cooking, gardening, and health-related issues, their significance goes beyond this. The pamphlets show that colonial Australian women's lives were far richer than some social theorists would have us believe - women had multiple roles in the developing nation - they were mothers and wives; managers of households, farms and businesses; medical and health practitioners; and perhaps travel coordinators.

\subsection{Colonial Pamphlets - Content and Style}

Taken as a whole, early Australian pamphlets are remarkably modern looking, many with contents pages or indexes, resembling books rather than brochures or essays, and sold for a cheap price. While the paper is usually low quality, the printing is more than adequate with modern looking frontispieces, headings, and many with illustrations and some with photographs. Pamphlets showed structure and organisation befitting a judicious audience used to reading practical texts. It is obvious that publishing of public lectures and sermons was a common practice in the colony, and from the sheer number and diversity of publishers, it was a developed industry.

\subsubsection{Educational pamphlets}

In many ways all pamphlets are educational or instructional, just by their very nature of seeking to inform or communicate a point of view. Thus both the religious and secular categories can be theorised as being pedagogical in nature. However, it is seldom realised that pamphlets functioned as a replacement for formal education especially in remote areas of the vast reaches of colonial Australia [19]. If a farmer or his wife wanted information on a particular aspect of agriculture, animal husbandry, raising of children or even music, then they could buy a cheap publication to meet their need for understanding and knowledge. Obviously this was not an organised course of study developed by a professional educator, but more a longish generalexposition, that would hopefully answer esoteric questions important to a diverse range of issues and problems.

Some wide-ranging titles in the archive include the following:

- Advice Gratis: Being Friendly Hints to Parents Touching the Training and Education of Their Children, Some Pernicious Habits Injurious to Health, and a Few Words on the Subject of Courtship and Marriage (1885).

- The First Few Months of Infancy Being Hints to Mothers 2nd ed (1888). 
- Thought Reading and Kindred Subjects (1886).

- Australian Butterflies, a Brief Account of the Native Families with a Chapter on Collecting and Preserving Insects (1889).

- A Brief Account of the Natives of Western Australia, Their Character, Manners, and Customs (1870).

- The Inventor's Guide to Obtaining and Selling Patents (1890).

- Hints on Infant and Elementary Music Teaching (1892).

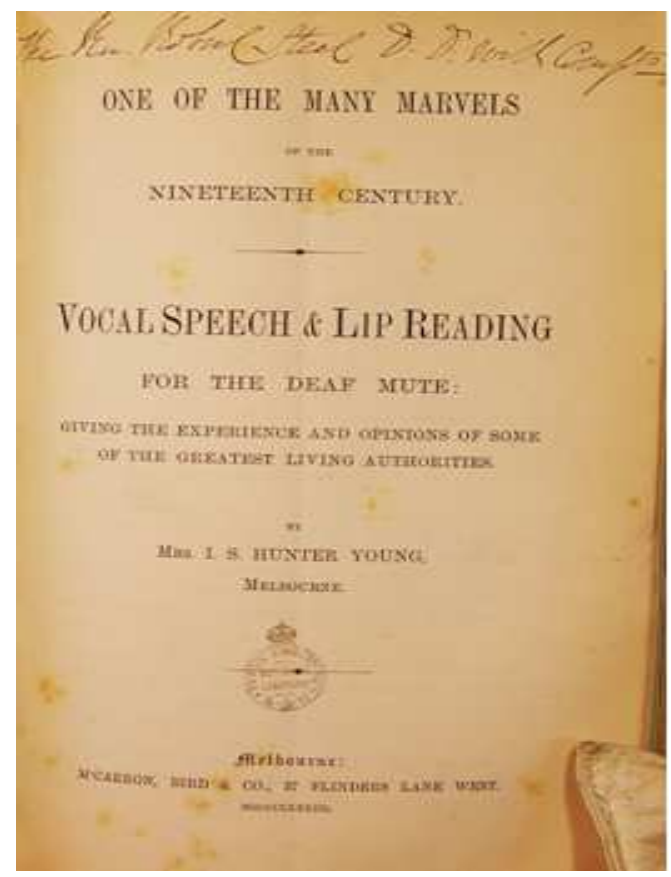

Fig. 1. an educational pamphlet.

\subsubsection{Medical and Health pamphlets}

The Medical/Health category was one of the most popular, amongst Renaissance books [6] and was seemingly just as popular in terms of colonial pamphlets. Colonial medical practitioners would have been in short supply, and an extravagance for most people, even the middle class. Thus the how-to guides explain home cures using herbal remedies, ways of staying healthy, and dietary/exercise regimes. One noteworthy pamphlet warns of the dangers of using tobacco in excess, even though pipe smoking was a commonplace habit amongst men and women. The medical and health-related examples in the archive are fairly diverse in content and style and include:

- What to Do in Cases of an Accident and Everyday Complaints: A Manual of Plain Treatment and Ready Remedies for Cases of Emergency (1884).

- The "Lepper" Dietary Cure: A Remedial and Curative System, obviating use of Drugs, and nowise weakeing the System (1889).

- Evidences of the Benefits of Homeopathy and Statistics of its Success (1863).

- The Hand and Physiognomy of the Human Form in Reltion to the Mind (1868).
- The Eye and its Care: Some Advice (1878).

- Does It Pay to Smoke (1869) and the Use and Abuse of Tobacco (1869) (combined in one pamphlet).

- Massage - its History, its Curative Uses, and its Practical Results (1890).

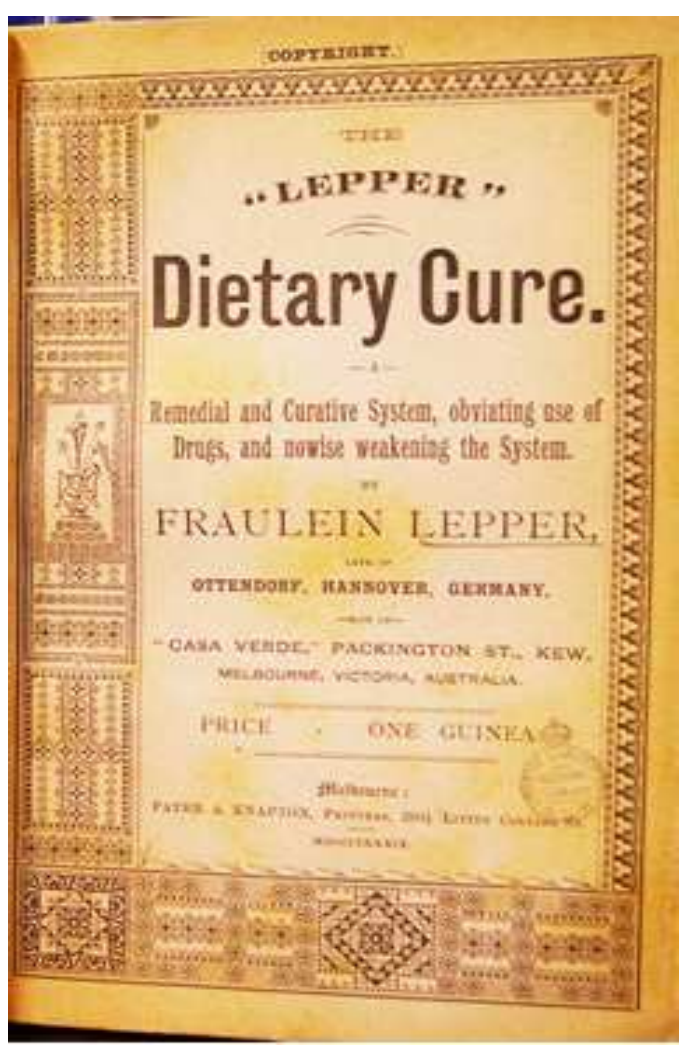

Fig. 2. a health-related pamphlet.

\subsubsection{Farming and Animal Husbandry Pamphlets}

The farming of crops and the raising of animals in Australia was, and still is, an important economic necessity for rural Australians. Food production and food preparation concern us all, and was a pre-occupation for our colonial ancestors. The early capital cities were comparatively small in geographic area, with many people living on city outskirts on semi-rural land. It was this audience that especially needed advice on a range of different crops, agricultural techniques, and livestock diseases. Some of the pamphlet titles include:

- An Essay on the Making of Wine (1844).

- The Silkworm (1861).

- Beekeeping and Honey in Australia (no date).

- Hints on the Purchasing of Horses (1855).

- Pamphlet Descriptive of the Timber-Creosoting Process to Waterproof, Season and Preserve Wood (1860).

- The Art of Tea Blending (1882).

- On the Cultivation of the Cotton Plant in NSW (1859).

- Grass and Sheep Farming - a Paper (1873).

- A Practical Treatise on the Cultivation of Sugar Cane and the Manufacture of Sugar (no date).

- On the Culture of the Tobacco Leaf (1877). 


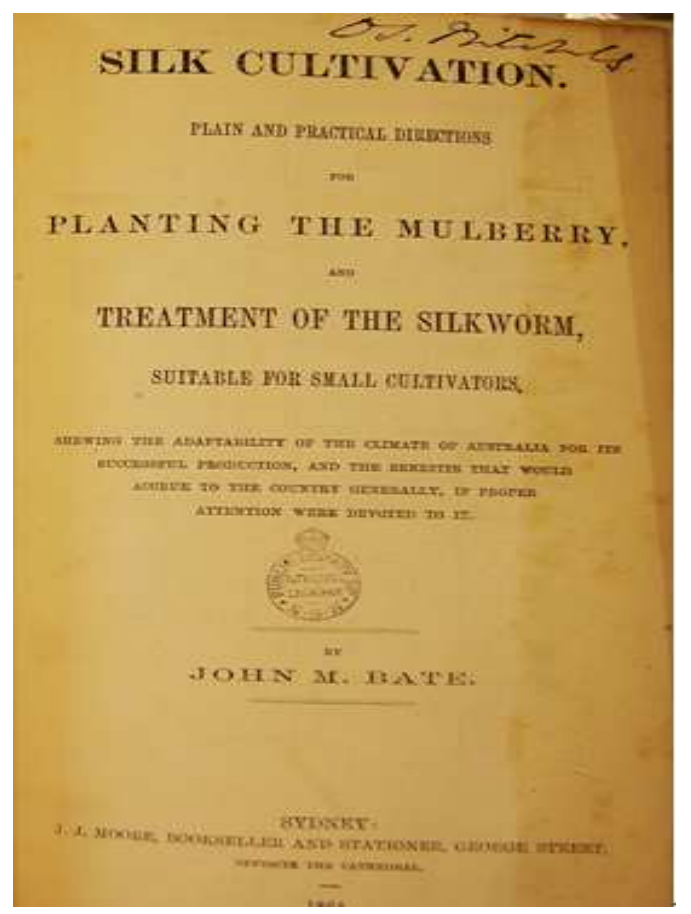

Fig. 3. a farming pamphlet.

\subsubsection{Gardening Pamphlets}

The number and variety of pamphlets on farming and animal husbandry show that these topics were of perennial interest to colonial readers. Pamphlets on gardens were nearly as popular since their appeal was to city and rural populations. Gardening is also an ancient human activity that suits both male and female readers, of any age and class of society. As stated earlier, plants were extensively used for medicinal and nutritional reasons, with many households cultivating a small garden of vegetables and herbs. Gardening pamphlets and books were popular during the English Renaissance, and later their counterparts were written for contemporaneous audiences in Australia, America and Europe in a variety of languages. Some of the gardening titles include:

- Lectures on the Horticulture of New South Wales (1835).

- Prickly Comfrey: its Historical Cultivation, Extraordinary Production and Uses (1878).

- The Queensland Horticulturalist and Gardener's Guide (1886).

- Handbook on Viticulture for Victoria (1891).

- The Australian Gardener (1858).

- The Gardener's Magazine (1855).

\subsubsection{Supernatural, Occult and Bizarre Pamphlets}

The number of pamphlets dealing with spiritualism, mind reading, astrology, palmistry, and circus freaks were numerous and surprising, given the highly religious nature of much of the Mitchell collection of ephemera. These topics are seldom mentioned in Australian history books or social treatises, but were obviously popular with the colonial public.

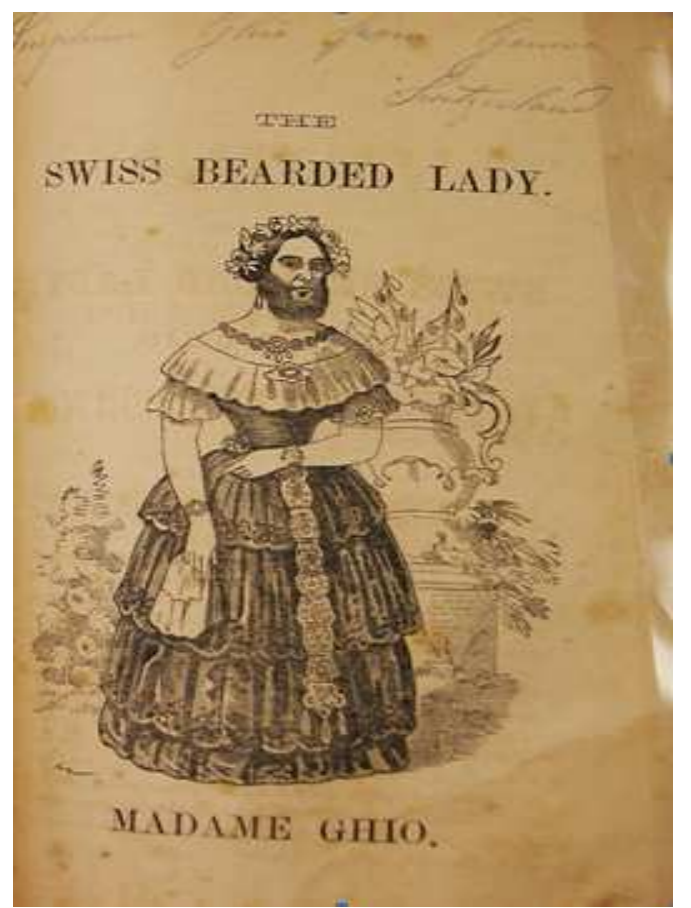

Fig. 4. an illustration from Biography of the Celebrated Swiss Bearded Lady, Madame Ghio and her son, Esau.

People through the ages have always been interested in supernatural phenomena probably due to fear of unusual occurrences, and special individuals. The witch hunts of the Middle Ages continued well into Elizabethan times, and most probably found a safer guise in formal depictions of magical powers and spiritual processes. Their depiction in colonial pamphlets reveals that many early Australians were both religious and superstitious, believing in the power of God, but also believing in other worldly powers that could be learned from texts. The pamphlets describing how to get in touch with spirits are fascinating documents - often countermanded by pamphlets that debunk these supernatural processes. Some of the titles include:

- Biography of the Celebrated Swiss Bearded Lady, Madame Ghio and her son, Esau (1863).

- Palmistry as a Pastime (no date).

- The Secrets and Ceremonies of Freemasony Exposed (1862).

- The Textbook of Mesmerism (1881).

- Further Light Upon the Mysteries of Spookland (no date).

- Physiological and Phrenological Chart (1892).

- Spiritualism: Its Outbreak Shown to be Predicted, and Its Dangerous Character Exposed, A Sermon (1872).

- An Essay on the Nature of the Phenomena called Possession by Evil Spirits (no date).

- How to Become a Ventriloquist (1878).

\subsubsection{Mining and Migration pamplets}

The population of Australia more than trebled between the years 1851 and 1871 due to an influx of migrants attempting to strike it rich in the goldfields of every state of Australia. Edward Hargreaves was an English free immi- 
grant who supposedly discovered gold at Bathurst about $250 \mathrm{Km}$ west of Sydney. Word of this spread like wildfire and goldfields were opened in both NSW and in Victoria which boasted lucrative mining sites at Bendigo and Ballarat. Western Australia, Queensland, Tasmania and the Northen Territory soon follwed suit with their own goldfields. The huge injection of capital, both financial and human, assured the viability of the once small English colony, and was one of the main reasons why independence for Australia was guaranteed a few decades later.

By 1901 Australia had become the largest producer of gold in the world, half of which came from Western Australia. For half a century, the gold rush emptied the major cities of administrators, teachers, policemen, civil servants, and ship's crews who abandoned their jobs in order to dig for gold. If one did not have any experience with this process, or if one wanted to migrate to Australia to dig for gold, then all one needed to read was a pamphlet on this topic:

- Plain Statements and Practical Hints Respecting the Discovery and Working of Gold in Australia (1851).

- Notes of a Gold Digger and Gold Diggers Guide (1852).

- Observations Upon the Amalgamation and Other Modes of Obtaining Gold and Precious Metals (1872).

- Wattle Flat Gold Field, Western District, N.S. Wales (1872).

- Emigrant's Guide to Australia via the Cape of Good Hope (1885).

- Handbook for Emigrants to Queensland, Australia (1868).

- Gold and How to Get It (1894).

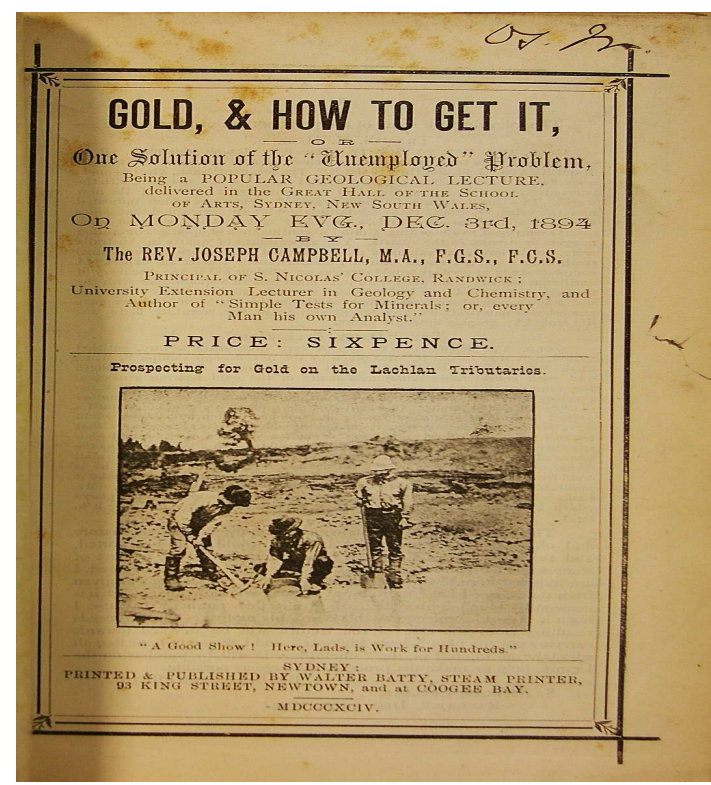

Fig. 5. a mining pamphlet.

\section{Conclusions}

Many Australians share a popular interpretation of their cultural heritage and identity, one that is similar to a myth- ical vision of colonial history. For most Australians, enculturation begins as school children are first introduced to textbooks about Captain Cook, Governor Phillip, the First Fleet, explorers, Bass and Flinders, the Eureka Stockade and the bushranger, Ned Kelly. After primary school, Australians learn through the media that the original inhabitants of Australia were displaced, and marginalised. Many Australians are shocked at the plight of Aborignal Australians. However, it is only through studying history that Australians might learn something of the everyday lives of their colonial ancestors. There were housing problems in the large capital cities, employment problems in the country towns, the abuse of alcohol and tobacco was a perennial problem for many working class men, and life was a constant struggle for most women. And whilst life would have been very difficult for the First Fleeters, for those miners who struck it rich on the goldfields, life would have been very comfortable.

The main sources for the school textbooks, the historical accounts, and the more specific studies of Australian colonial life are usually personal journals, published books and articles from early metropolitan newspapers. The missing element here is, of course, pamphlets, which may be seen as one of the forerunners to adult education, and in rural Australia, distance learning. Very few pamphlets are used in the various histories and interpretations of the birth of Australia (or any other country for that matter) or recounts of colonial life. Hopefully more researchers will seize and utilise the incredible richness found in these fragile documents and breathe even more life into the early beginnings of other communities from other parts of the world, as well as Australia.

\section{Additional Pamphlets}

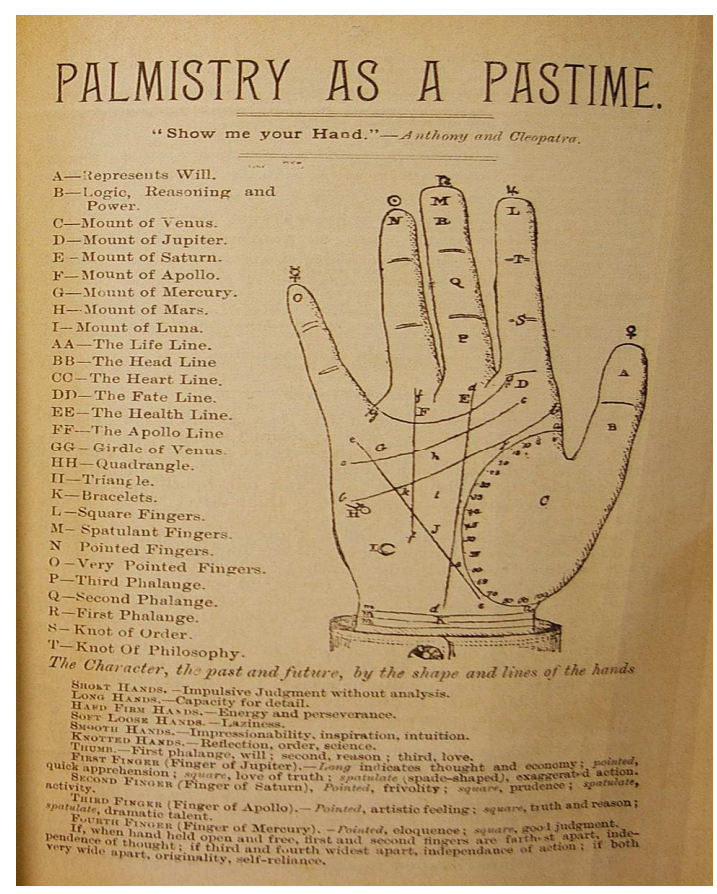



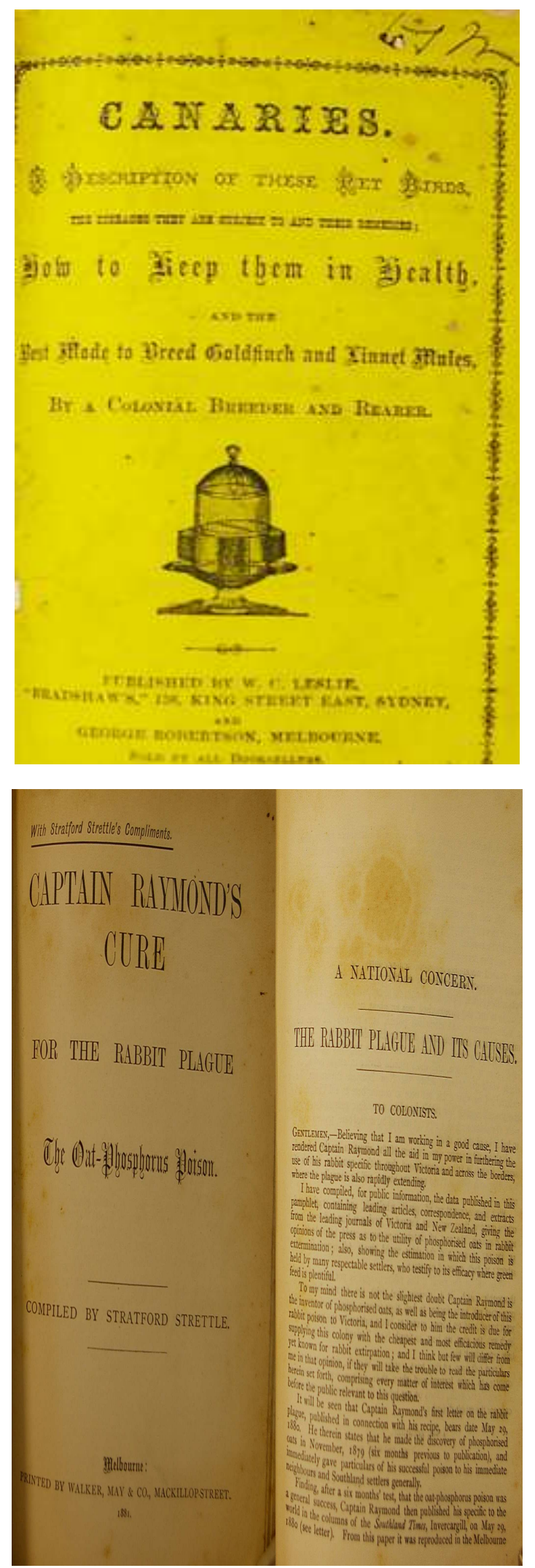

\section{2}

H I N T S

on

\section{INFAIT AND ELEIENTARY MUSIC TEACHING,}

BEING NOTES OF THREE LECTURES.

S. MoBURney, Mus. Doc.

ALEX. MFINLEY \& CO., PRINTERS AND PUBLISHER (Ofhick of "Avatralastax Schooharastre"),

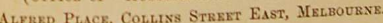
$\overline{1892}$.

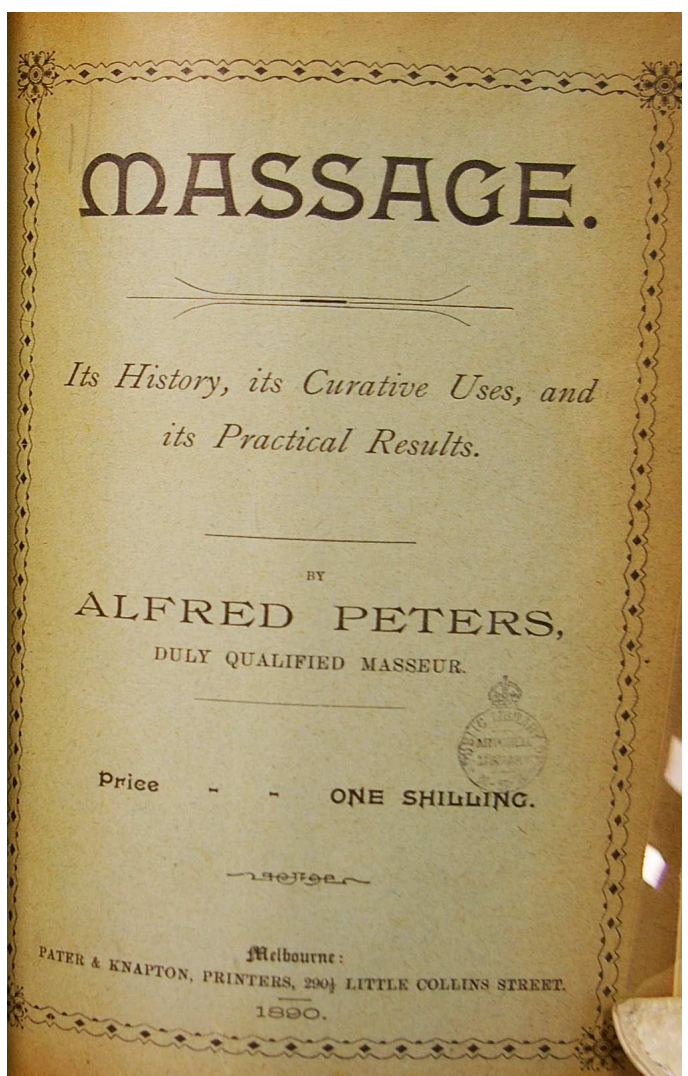




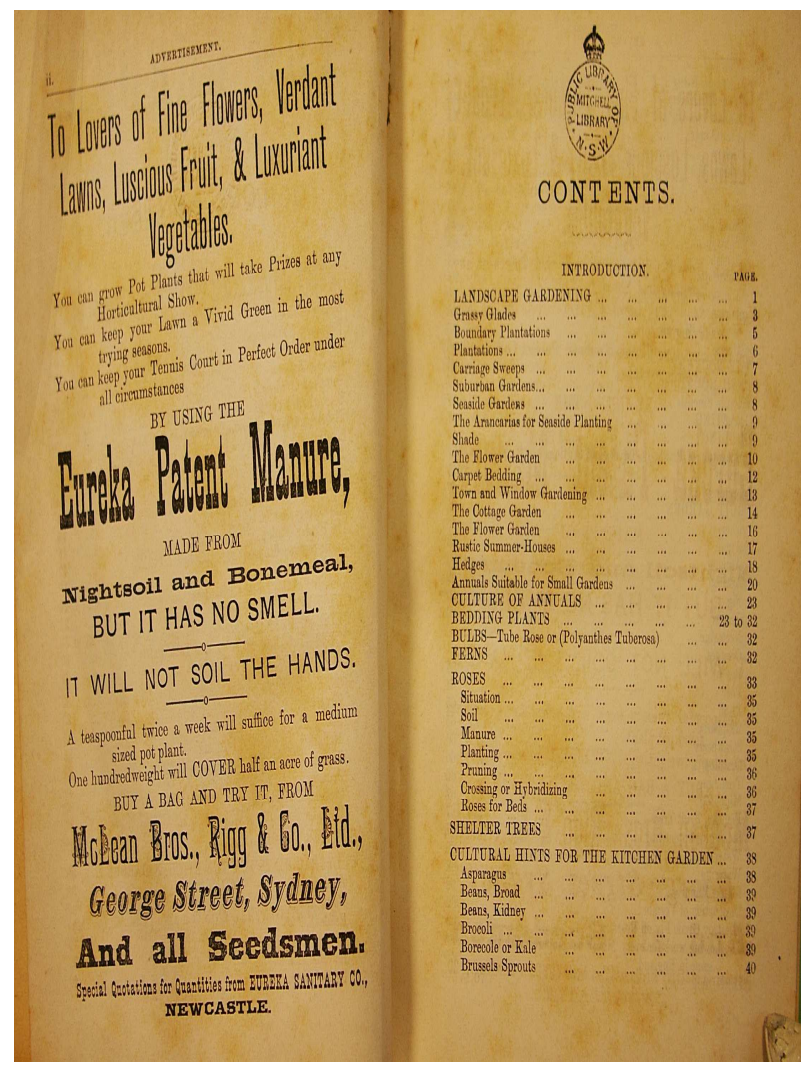

Excerpt from The Garden (1890).

\section{References}

[1] J. Raymond, Pamphlets and Pamphleteering in Early Modern Britain. Cambridge University Press, 2006.

[2] M. Davies,Icon Libellorum, or a Critical History of Pamphlets, London: booksellers of London and Westminster, 1715.

[3] H. Herd,The March of Journalism: The Story of the British Press from 1622 to the Present Day. London: George Allen \& Unwin, 1952.

[4] C. Mullett, "The historian and the use of pamphlets." The Library Quarterly, 5: 3 (Jul.), 301-322, 1935.

[5] L.B. Wright, Middle Class Culture in Elizabethan England, Cornell University Press, Ithaca: New York, 1958.

[6] E. Tebeaux, The Emergence of a Tradition: Technical Writing in the English Renaissanace, 1475-1640. NY: Baywood Publishing, 1997.

[7] K. Chaemsaithong, K. "Linguistic and stylistic constructions of witchcraft and witches: A case of witchcraft pamphlets in early modern England", PhD dissertation, 2007, Uni of
Washington. Online document: Retrieved 21/3/09. http://gradworks.umi.com/32/65/3265310.html.

[8] D. Charlesworth, Marketing Menopause and Inventing Identities: A Rhetorical Analysis of the Persona Created in Menopause Education Pamphlets. Paper presented at the annual meeting of the NCA 93rd Annual Convention, TBA, Chicago, IL, Nov 15, 2007. Online document: Retrieved 21/3/09.

http://www.allacademic.com/meta/p194669_index.html.

[9] R. Hoeflin, "Review: Public Affairs Pamphlets", Marriage and Family Living, 14: 2 (May), 186-188, 1952.

[10] K. Witte, "A Meta-Analysis of Fear Appeals: Implications for Effective Public Health Campaigns". Health Education \& Behavior, 27: 5, 591-615, 2000

[11] L. Meillier, M. Osler, S. Sabroe, B. Christense, P. Elsass, and L. Meyer, "Health education pamphlets about smoking-their benefit to smokers and non-smokers". Public Health, 113: 1, 19-25, 1999.

[12] C. Smith-Rosenberg, "Sex as Symbol in Victorian Purity: An Ethnohistorical Analysis of Jacksonian America". The American Journal of Sociology, 84, Supplement: Turning Points: Historical and Sociological Essays on the Family, S212-S247, 1978.

[13] K. Siegel, P.B. Grodsky, and A. Herman, A.,"AIDS risk-reduction guidelines: A review and analysis". Journal of Community Health, 11: 4, 233-243, 1986.

[14] S.C. Jones, "A review of the consistency of breast cancer screening pamphlets produced by health authorities in Australia", Health Education, 103: 3, 166 - 176, 2003.

[15] K.N. Kline, and, M. Mattson, "Breast Self-Examination Pamphlets: a Content Analysis Grounded in Fear Appeal Research", Health Communication, Vol. 12, 2000,http://www.questia.com/.

[16] J.L. Hunter, "Cervical Cancer Educational Pamphlets: Do They Miss the Mark for Mexican Immigrant Women's Needs?" Cancer, Culture and Literacy Supplement, pp, 42-50, Cancer Control, Nov 2005. Online document: http://www.moffitt.org/CCJRoot/v12s5/pdf/42.pdf.

[17] G. Loeben, T. Marteau, and B. Wilfond, B. "Mixed Messages: Presentation of Information in Cystic Fibrosis-Screening Pamphlets". The American Journal of Human Genetics, 63: 4, $1181-1189,1998$

[18] E. Tebeaux and M. Lay, "Images of Women in Technical Books from the English Renaissance", IEEE Transactions on Professional Communication, 35: 4, 196-207, 1992.

[19] A.G. Austin, and R.J.W. Selleck, The Australian Government School 1830-1914: Select Documents with Commentary. Pitman Publishing, Carlton, Vic, Australia, 1977. 